\title{
TEORIA LITERÁRIA EM QUESTÃO: O ENSINO DE LITERATURA NOS LIVROS DIDÁTICOS
}

\section{LITERARY THEORY IN QUESTION: THE TEACHING OF LITERATURE IN DIDACTIC BOOKS}

Walter Guarnier de Lima Júnior ${ }^{1}$

Recebido em: 02 nov. 2018

Aceito em: 21 mar. 2019

DOI 10.26512/aguaviva.v4i1.23845

RESUMO: Este artigo, num primeiro momento, retoma e problematiza duas das principais discussões levantadas pelos formalistas russos no início do século XX (CHKLOVSKI, 1973; EIKHENBAUM, 1973) quando fundam as bases do estudo teórico-metodológico da literatura: o conceito de "literariedade" e a noção de "estranhamento". Redirecionando os estudos literários empreendidos até então, Viktor Chklovski publica, em 1917, o ensaio $A$ arte como procedimento, censurando veementemente os simbolistas, que entendiam a arte como consequência de imagens mutáveis. Oito anos depois, Boris Eikhenbaum, em 1925, por meio do ensaio A teoria do "método formal", anuncia um método que abandonaria a ideia de evolução literária; reunindo, com isso, os pressupostos do movimento. Por meio dessas publicações, opunham-se à crítica impressionista das obras, defendendo um estudo sistemático e dissociado de seus elementos externos. Após breve retorno aos dois estudos que se opuseram aos princípios da história literária, buscaremos, por meio da análise de livros didáticos, utilizados por professores de português do Ensino Médio, identificar e discutir os reflexos da teoria literária no atual ensino de literatura considerando o contexto das escolas públicas e particulares do Distrito Federal.

Palavras-chave: Formalistas russos; Literariedade; Estranhamento; Recurso pedagógico.

\begin{abstract}
This article, at first, resumes and problematizes two of the main discussions raised by the Russian formalists at the beginning of the 20th century (CHKLOVSKI, 1973; EIKHENBAUM, 1973) when they found the bases of the theoretical-methodological study of literature: the concept of "literacy" and the notion of "estrangement". Redirecting the literary studies undertaken so far, Viktor Chklovski publishes, in 1917, the essay Art as procedure, vehemently censuring the symbolists, who understood art as a consequence of mutable images. Eight years later, Boris Eikhenbaum, in 1925, through the essay The theory of the "formal method", announces a method that would abandon the idea of literary evolution; gathering the assumptions of the movement. Through these publications, they opposed the impressionist critique of works, defending a systematic and dissociated study of their external

1 Doutorando em Estudos Literários - PPLET, Universidade Federal de Uberlândia (Minas Gerais), Mestre em Linguística Aplicada pela Universidade de Brasília (UnB) e Professor-Assistente do Centro Universitário IESB de Brasília. E-mail: walter.guarnier@outlook.com.br
\end{abstract}


elements. After a brief return to the two studies that opposed the principles of literary history, we will seek, through the analysis of textbooks, used by teachers of portuguese of High School, to identify and discuss the reflexes of literary theory in the current literature teaching considering the context of the public and private schools of the Distrito Federal.

Keywords: Russian Formalists; Literacy; Estrangement; Pedagogical Resource.

\section{INTRODUÇÃO}

Resultando de algumas correntes, dentre elas o formalismo russo, que no início do século XX se opôs aos princípios da história literária, a teoria da literatura, privilegiando e enaltecendo uma perspectiva estética, propôs-se a investigar a literatura em sua essência, isto é, voltando todas suas atenções para o próprio texto, deixando em segundo plano dados extra textuais como a vida do autor e os reflexos históricos presentes na obra. É uma disciplina modernista associada a uma ideia de literatura como autoreferência, desvinculada do conceito de obra literária como representação, comum nas concepções romântico-realistas da história literária.

Este artigo busca, num primeiro momento, revisitar dois dos principais conceitos levantados pelos formalistas russos nas primeiras décadas do século XX: a ideia de "literariedade" e a noção de "estranhamento", termos que entraram para a história da disciplina ao fundarem as bases do estudo teórico-metodológico da literatura. Na tentativa de encontrar propriedades nas obras literárias que as denominassem pertencentes à literatura, os teóricos do formalismo chegaram ao conceito de literariedade. O estranhamento, por sua vez, nasceu a partir das discussões entre os formalistas russos e as ideias defendidas por Aleksandr Potebnia, um dos representantes do simbolismo russo. Segundo Chklovski (1973), o estranhamento estaria relacionado ao efeito criado por uma determinada obra a fim de distanciar (ou estranhar) o leitor do modo corriqueiro e comum que apreende o mundo, permitindo-o, pelo olhar estético, adentrar uma nova dimensão, perceptível apenas através da arte.

Após breve retorno aos formalistas russos, que se opuseram aos princípios da história literária, buscaremos, num segundo momento, analisar dois livros didáticos - Português: linguagens, de William Roberto Cereja e Thereza Cochar Magalhães, e Literatura em contexto: a arte literária luso-brasileira, de Clenir Bellezi de Oliveira - utilizados por escolas 
de Brasília, a fim de identificar e discutir possíveis reflexos da teoria literária no atual ensino de literatura, considerando o contexto das escolas públicas e particulares do Distrito Federal.

A fim de facilitar a leitura e a compreensão da temática levantada, dividimos a discussão em apenas duas seções. Na primeira - "Formalismo russo: literariedade e estranhamento" - discorremos sobre: formalismo russo, literariedade, estranhamento e teoria literária. Na segunda seção - “A teoria literária nos livros didáticos” - Apresentamos os livros didáticos selecionados, seguidos de suas respectivas análises, carregadas de reflexões pessoais e teóricas. Por fim, ao final do artigo, encerramos nossas discussões apresentando, nas considerações finais, alguns comentários construídos ao término do estudo empreendido.

\section{Formalismo Russo: literariedade e estranhamento}

No início do século XX, vivenciávamos uma tendência histórica literária bastante forte, fundamentada em ideias marcadamente positivistas. Tal perspectiva literária focava, em especial, apenas os aspectos de erudição encontrados nas obras analisadas, pouco, ou nada, se importando com seus valores estéticos. A crítica literária, realizada durante esse período, em diversos meios de comunicação (jornais, revistas, por exemplo), era extremamente impressionista e, em consequência disso, pouco séria. Tal contexto, o "pré-formalismo", por assim dizer, em que a crítica priorizava, em suas análises, aspectos biográficos, históricos, sociais e filosóficos, marcou o início das inquietações que farão surgir o formalismo russo.

Descontentes com os modelos acadêmicos vigentes, alunos ingressantes em renomadas universidades eslavas iniciaram uma incessante busca por novas orientações, reunindo-se em dois grupos de estudos: o "Círculo Linguístico de Moscou" - CLM, na Universidade de Moscou, e a "Sociedade para o Estudo da Linguagem Poética" - Opojaz, em São Petersburgo.

Fundado aproximadamente entre 1914-1915, por Roman Jakobson, o CLM reuniu um seleto grupo de jovens alunos da Universidade de Moscou (dentre eles, os famosos: Roman Jakobson, Viktor Chklovski, Boris Eikhenbaum) com o objetivo de estudar, de modo mais "preciso" e sistemático, a língua e a poética. Empreendendo um rigoroso estudo "objetivo" sobre a estrutura de diversos gêneros literários (narrativas, contos, poemas, etc.), buscavam, neles, a "literariedade" (termo que discutiremos com mais profundidade adiante). A ideia do grupo, grosso modo, era a de investigar a composição desses textos a fim de fundar uma 
ciência literária, mais racional, objetiva, desvinculada do impressionismo experienciado na corrente anterior.

Fundado em 1916, em São Petersburgo, e liderado por Chklovski, o Opojaz se dedicará ao estudo do método formal, utilizando a técnica na análise das obras literárias. Segundo seus membros, as obras se assemelhariam às máquinas, pois seriam o resultado do emprego da ação e da força humanas intencionais, em que determinadas habilidades, do autor, transformam, com um determinado propósito, a matéria bruta em arte, através de um complexo e ardiloso mecanismo de produção. Tal perspectiva teórica extrai, do processo de investigação e análise, qualquer possibilidade de interferência do autor, leitor e seus respectivos contextos históricos.

Como pode ser observado, o que denominamos de "formalismo russo" foi, na verdade um movimento múltiplo, que, em virtude de sua própria fragmentação, não produziu um aparato teórico único, tampouco direcionou seus membros a um consenso sobre a matéria discutida. Desse modo, é mais preciso adotarmos a expressão "formalistas russos" em vez do termo "formalismo", mais amplo e vago.

Por que "formalistas"? Por que "formalismo"? Por que e como surgiram essas denominações para definir os dois grupos? A ideia de "forma" atribuída aos membros dos grupos de estudo russos, através dos termos "formalismo" e "formalistas", foi empregada por seus adversários e explicitamente rejeitada pelos formalistas eslavos, nas palavras de Eikhenbaum:

[...] os principais esforços dos formalistas não se conduziram para o estudo da chamada forma, nem para a construção de um método particular, mas de que êles (sic) visavam estabelecer a tese segundo a qual devemos estudar os traços específicos da arte literária [...] Quanto a palavra "forma", importava aos formalistas modificar o sentido dêste (sic) termo confuso a fim de não mais ser molestado pela associação corrente que se costumava fazer com a palavra "fundo" cuja noção era ainda mais confusa e menos científica. Importava destruir a correlação tradicional e enriquecer a noção de forma com nôvo (sic) sentido (EIKHENBAUM, 1973, p. 15, grifo nosso).

Ao contrário do que defendiam seus opositores, o formalismo russo é caracterizado, principalmente hoje, pela ênfase que deu ao aspecto funcional dos elementos literários, além de apresentar uma nova e original percepção sobre a história literária. Defendiam, ainda, um método "científico", por assim dizer, para investigar os aspectos literários do texto, excluindo toda e qualquer abordagem de caráter biográfico, psicológico e/ou histórico cultural. Dessa forma, podemos dizer que a investigação formalista era orientada por dois princípios básicos: 
a literatura, por si mesma, ou, mais precisamente, as características que a diferenciavam de outros objetos provenientes da ação humana e o foco nos fatos literários, em detrimento dos elementos metafísicos utilizados pela crítica. Por fim, concordavam sobre a autonomia da linguagem poética, como objeto de estudo, se empenhando em estabelecer suas propriedades características, tanto na prosa quanto na poesia, reconhecidas pela essência artística.

Durante o processo de investigação sobre a arte poética, os formalistas russos cunharam na teoria literária dois termos, "literariedade" e "estranhamento", que são, até hoje, usados com muita frequência e estudados, tanto na educação básica quanto nas altas esferas acadêmicas.

Os formalistas, através dos estudos que empreenderam, queriam identificar uma propriedade específica, existente nos textos literários, que os enquadrasse dentro do escopo do que se entendia como literatura. Tal propriedade ganhou o nome de "literaturnost", traduzido, em seguida, para "literariedade". Segundo eles, a ciência literária que se estava buscando construir deveria se dedicar ao estudo dessa propriedade, ou seja, a literariedade presente nos textos, aquilo que confere a uma determinada obra sua essência literária. Esse procedimento conduziu os formalistas a estabelecerem certos limites quanto aos caracteres do fenômeno literário. A propriedade que buscavam estaria no próprio texto e seria algo imanente a ele, que deveria ser tomado como objeto de investigação sistemática.

Boris Eikhenbaum, em 1925, por meio do ensaio A teoria do "método formal", defende o procedimento de análise elaborado, criado especialmente para combater as velhas tradições. Segundo ele,

[...] o método formal superou completamente os limites do que chamamos geralmente metodologia e com ele se transformou numa ciência autônoma tendo por objetivo a literatura considerada como série específica de fatos (EIKHENBAUM, 1973, p. 04).

Após breve defesa do método que será apresentado durante o ensaio, Eikhenbaum se dedicará à "descrição" do novo procedimento de análise, sob a justificativa de criar uma ciência literária autônoma, a partir das qualidades intrínsecas do material literário. Iniciará as discussões, afirmando que:

Após ter deixado de lado inúmeros problemas gerais como o problema do belo, do sentido da arte, etc., êstes (sic) estudos [os que empreendeu] se concentraram sôbre (sic) os problemas concretos propostos pela análise da obra de arte (EIKHENBAUM, 1973, p. 05). 
Nessa afirmação, Eikhenbaum explica que em seu ensaio focará apenas as questões concretas dos textos, excluindo da discussão questões relacionadas ao "belo" e ao "sentido" da arte.

Depois de afirmar que "O objeto da ciência literária não é a literatura, mas a 'literaturidade"” (EIKHENBAUM, 1973, p. 08, grifo nosso), um primeiro esboço do termo "literariedade", o formalista, no intuito de explicar a essência do novo método, se dedica, num primeiro momento, a diferenciar a "língua poética" da "língua quotidiana". Em sua definição de língua poética, objeto de sua investigação, por abrigar a literariedade, aponta que:

[...] não é unicamente uma língua de imagens e que os sons do verso não são sòmente (sic) os elementos de uma harmonia exterior, que não só acompanha o sentido, mas que éles (sic) próprios têm uma significação autônoma (EIKHENBAUM, 1973, p. 11).

A partir disso, fica evidente que o trabalho dos formalistas começou pelo estudo do problema dos sons do verso, ou seja, algo extremamente concreto, estrutural, como declarado pelo próprio Eikhenbaum.

Ainda em seu texto, rebate ao simbolismo de Aleksandr Potebnia, afastando-se da relação forma-fundo e da noção de forma como invólucro:

Distanciando-se de Potebnia, os formalistas se livravam da correlação tradicional de forma-fundo e da noção de forma como invólucro, como um recipiente no qual se deposita o líquido (o conteúdo). Os fatos artísticos testemunhavam que a differentia specifica da arte não se exprimia através dos elementos que constituem a obra, mas através da utilização particular que se faz dêles (sic) (EIKHENBAUM, 1973, p. 13, grifo do autor).

Através da citação anterior, podemos perceber que para Eikhenbaum, e para os demais formalistas, a forma não deveria ser estudada de forma isolada e descontextualizada, como insinuavam seus opositores; mas considerando, em especial, o tipo de uso que os autores de textos literários fazem dela. Dessa maneira, a noção de forma, assumia, com os formalistas, um novo sentido, não sendo mais apenas um invólucro, mas uma integridade dinâmica e concreta que tem em si mesma um conteúdo. Assim, o caráter específico da arte estaria intimamente relacionado à utilização particular do material. 
[...] os principais esforços dos formalistas não se conduziam para o estudo da chamada forma, nem para a construção de um método particular, mas de que êles (sic) visavam estabelecer a tese segundo a qual devemos estudar os traços específicos da arte literária. Para isso, é preciso partirmos da diferença funcional entre a língua poética e a língua quotidiana. Quanto à palavra "forma", importava aos formalistas modificar o sentido dêste têrmo (sic) confuso a fim de não mais ser molestado pela associação corrente que se costumava fazer com a palavra "fundo" cuja noção era ainda mais confusa e menos científica. Importava destruir a correlação tradicional e enriquecer a noção de forma com um nôvo (sic) sentido (EIKHENBAUM, 1973, p. 15).

A forma poética, assim compreendida, não se opunha a um fundo que lhe seria exterior, mas seria tratada como o verdadeiro fundo do discurso poético. As questões a respeito da arte poética teórica que haviam se iniciado nos primeiros trabalhos de seu grupo, passavam a ocupar, agora com o ensaio de Eikhenbaum, o centro do interesse dos formalistas russos. Assim, seria natural que, durante esse período, as obras literárias não representassem, para eles, mais que uma matéria própria para verificar e confirmar suas teses teóricas. Vale destacar, ainda, que o método formal, elaborado por Eikhenbaum e pelos formalistas, serviu de propaganda e oposição contra seus adversários.

Quando se fala do método formal e de sua evolução, é preciso dar atenção ao fato de que muitos dos princípios postulados pelos formalistas na época de discussão intensa com seus adversários tinham importância não somente (sic) como princípios científicos, mas também como slogans que, numa finalidade de propaganda e de oposição, se acentuavam até o paradoxo. (EIKHENBAUM, 1973, p. 15)

Através do levantamento dessas discussões, os formalistas russos, em especial Eikhenbaum, sistematizaram os problemas e fatos da história literária, tornando, assim, as premissas teóricas iniciais mais concretas e complexas. Ao final de seu ensaio, Eikhenbaum encerra afirmando que uma teoria que explica tudo, que dá respostas para todos os casos do passado e do futuro, sem a necessidade de uma evolução, seria admitir que o método formal morreu ou perdeu o seu espírito de pesquisa. Ou seja, por mais que tenha chegado à criação de um novo olhar para o texto literário, estabelecendo seus primeiros princípios teóricos, tem plena ciência de que este é apenas o início e não o fim do caminho.

O termo "estranhamento" foi usado por Viktor Chklovski, em 1917, no ensaio A arte como procedimento. Tal conceito surge a partir das discussões entre os formalistas russos e Aleksandr Potebnia, já mencionado anteriormente. Para este, “A arte é pensar por imagens [...] 
Não existe arte e particularmente poesia sem imagens [...] a poesia assim como a prosa é antes de tudo, e sobretudo, uma certa maneira de pensar e reconhecer (CHKLOVSKI, 1973, p. 39).

Como bem ilustrado, por meio da citação anterior, segundo Potebnia, a arte, através de suas imagens, tentava apresentar o desconhecido pautando-se pelo já conhecido. Discordando das ideias defendidas por Potebnia, Chklovski afirma, em seu ensaio, que a imagem é somente um dos inúmeros elementos que compõe o sistema de processos artísticos usados pelo autor. Ainda para ele, os conceitos de linguagem poética e de imagem não possuem o mesmo valor, pois estas podem surgir em diferentes níveis linguísticos e, da mesma forma, pode existir uma linguagem poética desprovidas de imagens. Para Chklovski, ao contrário de Potebnia,

O objetivo da arte é dar a sensação do objeto como visão e não como reconhecimento; o procedimento da arte é o procedimento da singularização dos objetos e o procedimento que consiste em obscurecer a forma, aumentar a dificuldade e a duração da percepção. $O$ ato de percepção em arte é um fim em si mesmo e deve ser prolongado; a arte é um meio de experimentar $o$ devir do objeto, o que é já "passado" não importa para a arte (CHKLOVSKI, 1973, p. 45, grifo do autor).

Partindo disso, o estranhamento, segundo Chklovski seria exatamente o efeito emanado pela obra literária a fim de nos distanciar e/ou criar certa sensação de estranhamento em relação ao modo costumeiro como depreendemos o mundo e a própria arte, o que nos permitiria então acessar uma nova dimensão, visível apenas por meio do olhar estético e/ou artístico. O estranhamento causado pela arte seria uma maneira de desautomatizar nosso olhar, seria uma espécie de instrumento para reavivar nossas percepções, que o hábito torna inertes. Ginzburg, em seu texto - "Estranhamento: Pré-história de um procedimento literário" - afirma que o estranhamento parece ser um antídoto eficaz contra um risco a que todos estamos expostos: o de banalizar a realidade, inclusive nós mesmos (GINZBURG, 2001, p. $41)$.

Como visto anteriormente, os formalistas russos, por meio de suas publicações, opunham-se à crítica impressionista das obras, defendendo um estudo sistemático e dissociado dos seus elementos externos. Assim, dois dos principais conceitos levantados pelos formalistas russos nas primeiras décadas do século XX - a ideia de "literariedade" e a noção de "estranhamento" - entraram para a história da teoria literária ao fundarem as bases do estudo teórico-metodológico da literatura.

Aparecem, na década de 1910, portanto, os primeiros sinais que anunciam uma circunscrição no campo dos modernos estudos literários. Essa nova disciplina, a teoria da 
literatura, a configurar-se num livro fundador, teria por missão, segundo Rodó (2011), “a educação da sensibilidade estética e do gosto", cabendo-lhe valorizar "o variado conteúdo da atividade literária própria da civilização e cultura modernas, segundo uma ordem fundamentada nas formas que realmente vivem". A teoria da literatura assim se inscreve no circuito do ensino e começa a buscar o seu espaço.

Seja lá como for, ainda que muitas vezes deixando perplexos não só os alunos, mas também professores, por sua natureza abstratizante e problematizadora, por seus desenvolvimentos nem sempre assinalados por economia e clareza metodológica e conceitual, o fato é que a teoria da literatura foi ganhando espaço. No sistema educacional brasileiro, estreia na década de 1960 e passa a concorrer com a literatura nacional, disciplina que a precedia exatamente de um século, ensinada que era entre nós desde 1860. Assim, se no começo não conseguiu fazer sombra à sua concorrente centenária, a partir de meados da década de 1970 já é a principal referência acadêmica na área dos estudos literários, e sua carreira vertiginosa aliás coincidiu com a estruturação da pós-graduação em Letras nas universidades brasileiras, onde seu ensino passaria a ter um lugar de destaque amplamente reconhecido (SOUZA, 2014, p. 33).

Por outro lado, os "anos de glória" da nova disciplina duraram pouco. Já na década de 1990 era sua vez de ficar na linha de tiro. Desta vez, os dispositivos vieram de uma grande novidade no campo da literatura, que responde pelo nome de estudos culturais.

\section{A teoria literária nos livros didáticos}

Após breve retorno, na seção anterior, aos dois principais estudos que se opuseram aos princípios da história literária, buscaremos, por meio da análise dos livros didáticos apresentada nesta seção, identificar e discutir os reflexos da teoria literária no atual ensino de literatura, considerando o contexto das escolas públicas e particulares do Distrito Federal.

Como se deu a escolha dos livros? Nosso objetivo norteador inicial, num primeiro momento, era apenas identificar possíveis reflexos e/ou pontos de diálogos entre a teoria literária e os livros didáticos de português utilizados atualmente por alunos do Ensino Médio. Num segundo momento, após algumas reflexões, percebemos que em vez de selecionar livros didáticos aleatoriamente, considerando apenas o período de escolarização em que são usados, seria mais enriquecedor, para a análise, pensá-los em contextos educacionais específicos. A partir dessa reflexão, decidimos escolher dois livros, todos utilizados em Brasília-DF: um em escolas particulares e o outro em escolas da rede pública. Para definir quais seriam os livros 
escolhidos, consultamos três livrarias da região a fim de identificar quais eram os livros de Português e/ou Literatura do Ensino Médio mais vendidos em 2017. Os dois livros, então escolhidos, foram exatamente aqueles que foram apresentados pelas três livrarias.

O primeiro livro, Português: linguagens (volume único), de William Roberto Cereja \& Thereza Cochar Magalhães, publicado pela Atual Editora, é utilizado atualmente nos três anos do Ensino Médio, em algumas das escolas da rede pública de ensino de Brasília-DF. Sua estrutura compreende não só os conteúdos de literatura, mas intercala esta com os conteúdos de gramática e produção de texto. Está dividido em nove grandes unidades, com uma média de sete capítulos cada.

Como no Ensino Médio não há uma obrigatoriedade, por parte do Governo Federal, em fornecer os livros às escolas públicas, fica a critério destas instituições a adoção de outras estratégias a fim de adquirir tais recursos para a utilização nas aulas. De todas as possíveis estratégias utilizadas, a mais recorrente é o repasse, para o estudante e/ou responsável, da compra do material. Assim, a escola faz a seleção do livro e, por meio das informações fornecidas pelo professor de cada disciplina, o aluno faz a sua aquisição. Por uma questão de custo benefício, e considerando a realidade social dos estudantes, as escolas preferem sugestões de livros que integrem em um único volume os três principais conteúdos da área de linguagens: gramática, produção de texto e literatura. No caso da literatura, em especial, temos uma particularidade, pois nem todas as escolas têm um professor e/ou horário destinado exclusivamente ao trabalho com a disciplina. Em boa parte das escolas, é o professor de português quem define, dentro da sua carga horária, "se" e "quando" irá trabalhar literatura.

A primeira referência à teoria da literatura, no livro Português: linguagens, se dá logo no capítulo inicial - "Linguagem, comunicação e interação". Ainda que de modo indireto, seus autores, Cereja e Magalhães, retomam as discussões realizadas pelos formalistas russos, em especial as levantadas por Roman Jakobson, referentes à teoria da comunicação.

Para descrever e analisar uma situação de comunicação, Jakobson propõe, em sua teoria da comunicação, que se considere seis elementos essenciais [locutor, locutário, mensagem, código, canal e referente] [...] Segundo Jakobson, é possível determinar funções da linguagem com base nas características dos textos e nas intenções do locutor. Assim, a linguagem desempenharia uma ou outra função, de acordo com o elemento da comunicação posto em foco pelo locutor [...] Desse modo, a cada um dos elementos da comunicação Jakobson associou uma função da linguagem: emotiva, conativa, referencial, metalinguística, fática e poética (CEREJA \& MAGALHÃES, 2013, p. 20-21, grifo nosso). 
Independentemente da ênfase linguística, percebemos que sutilmente a literatura, com o auxílio de Jakobson, através da função poética, começa a ganhar, no livro didático, seus primeiros traços teóricos, confirmados com a citação a seguir: "Função poética - A mensagem é o foco, ou seja, ela determina as escolhas feitas na construção do texto" (CEREJA \& MAGALHÃES, 2013, p. 24, grifo nosso). Os dois fragmentos selecionados, "A mensagem é o foco" e "construção do texto", deixam claras as intenções dos formalistas, investigar a literatura em sua essência, isto é, voltando todas as suas atenções para o próprio texto, deixando em segundo plano dados extratextuais como a vida do autor e os reflexos históricos presentes na obra. Eikhenbaum, no texto A teoria do "método formal", chega a levantar a questão da linguagem poética, diferenciando-a de uma linguagem oposta, a prosaica:

As vêzes (sic), não é a construção, mas a combinação de palavras, a sua disposição que é perceptível. A imagem poética é um dos meios que servem para criar uma construção perceptível que podemos experimentar na sua própria substância; mas ela não é nada demais... A criação de uma poética científica exige que se admita desde o início que existe uma língua poética e uma língua prosaica cujas leis são diferentes, idéia (sic) provada por inúmeros fatos. Devemos começar pela análise dessas diferenças (EIKHENBAUM, 1973, p. 15).

O diálogo com a teoria é nítido, ao demonstrar, no livro didático, que há uma função poética da linguagem, é preciso reconhecer que ela é dotada de uma estrutura peculiar que a diferencia das demais funções. Como bem destaca Eikhenbaum, a criação de uma poética científica, no período dos formalistas, exige que se admita a existência de uma língua poética e uma figura prosaica, cujas leis são diferentes. Ao que parece, a obra de Cereja e Magalhães, fundamentada em alguns postos do formalismo russo, tenta oferecer, aos estudantes do Ensino Médio, mesmo que de modo sutil e superficial, um curto momento onde sejam levantas e problematizadas essas diferenças existentes na linguagem, dependendo da função que assume.

No segundo capítulo - “O que é literatura?” - encontramos, de modo mais acentuado, os reflexos da teoria literária que resgatam as principais discussões levantadas pelos formalistas russos: a ideia de "literariedade" e a noção de "estranhamento". A "literariedade" aparece de modo bastante sutil na obra, há praticamente um apagamento do termo cunhado pelos formalistas. Na seção "A literatura e suas funções", identificamos o seguinte trecho: “(...) a literatura é uma linguagem especial, carregada de sentidos e capaz de provocar emoções e reflexão no leitor" (CEREJA \& MAGALHÃES, 2013, p. 33, grifo nosso). O que os autores definem como "linguagem especial"? Não fica claro! Estariam, eles, sugerindo 
como "linguagem especial" a "literariedade" apresentada por Jakobson, quando este declara que "O objeto da ciência literária não é a literatura, mas a 'literaturidade', (literaturnost), ou seja, o que faz de uma obra dada uma obra literária" (apud EIKHENBAUM, 1973, p. 8, grifo do autor)? Não sabemos! provavelmente esta será uma das perguntas que os alunos farão ao professor da disciplina.

Ainda na mesma seção "A literatura e suas funções”, identificamos, na obra, uma referência explícita a outro famoso formalista, quando seus autores declaram:

[...] a arte ainda cumpre o papel de proporcionar prazer e fruição estética e de aliviar as tensões da alma humana. Ou, na concepção do teórico russo Chklovski, o papel de provocar um estranhamento em face da realidade, como se nos desautomatizássemos e passássemos a ver o mundo com outros olhos (CEREJA \& MAGALHÃES, 2013, p. 33, grifo do autor).

Chklovski acreditava que a "automatização engole os objetos, os hábitos, os móveis, a mulher e o mêdo (sic) à guerra" (CHKLOVSKI, 1973, p. 44), por isso, Eikhenbaum afirmará que "A arte [através do estranhamento que provoca] é compreendida como um meio de destruir o automatismo perceptivo [...]”" (EIKHENBAUM, 1973, pp. 14-15).

Como foi possível observar, o primeiro livro, Português: linguagens (volume único), de William Roberto Cereja \& Thereza Cochar Magalhães, apresenta, em sua estrutura, alguns pontos que direta ou indiretamente dialogam com a teoria literária iniciada com os trabalhos desenvolvidos pelos formalistas russos ainda nas primeiras décadas do século XX.

O segundo livro, Literatura em contexto: a arte literária luso brasileira (volume único), de Clenir Bellezi de Oliveira, publicado pela Editora FTD, é utilizado atualmente nos três anos do Ensino Médio, em algumas das escolas particulares de Brasília-DF. É composto por 23 grandes capítulos e um apêndice que destaca a literatura brasileira dos últimos anos e a literatura africana de língua portuguesa.

As escolas particulares de Brasília, assim como boa parte das escolas particulares do Brasil, optam pela sugestão de livros que serão comprados pelos pais dos alunos para sua utilização no Ensino Médio. Neste contexto, como a realidade social é outra, diferente da realidade das escolas públicas, o material destinado à área de linguagem quase sempre vem fragmentado em três livros, sendo um para cada subárea da disciplina língua portuguesa: um livro para estudos gramaticais, outro para o trabalho com a produção de texto, por fim, um terceiro, com apenas o conteúdo de literatura. O contexto de utilização deste último recurso difere bastante do uso do livro anterior, visto que nas escolas particulares a literatura 
geralmente tem um professor e um horário específicos. Vale destacar ainda que, nestas escolas, há uma enorme cobrança por parte da instituição para um rigoroso cumprimento, pelo professor, do que é proposto pelo livro didático.

O segundo livro analisado, Literatura em contexto: a arte literária luso brasileira, ao contrário do primeiro, apresenta notoriamente uma perspectiva historiográfica da literatura, dando ênfase especial aos estilos de época, ponto facilmente percebido na divisão de seus capítulos, o que confirma a fala de Cury:

[...] no ensino médio, a literatura é estudada predominantemente sob o enfoque quase exclusivo dos estilos de época, muitas vezes desprezando trabalhos com os próprios textos e um juízo estético sobre eles (CURY, 1992, p. 54, grifo do autor).

É bem verdade que a obra traz uma enorme quantidade de textos literários, ao contrário da obra anterior, mas boa parte deles são fragmentados e sem critérios claros de seleção. Ainda segundo Cury,

\begin{abstract}
Boa parte das historiografias literárias, principalmente as que aparecem de forma reduzida nos livros didáticos, toma a classificação das obras como essência do trabalho interpretativo e crítico [...] Se, de um lado, as classificações são indispensáveis ao historiador da literatura, limitar-se a elas significa paralisar a historiografia tomando-a como um grande escaninho onde são afixadas as diferentes obras, desprezando-se o que não se encaixa, tornando homogêneo o que é díspar e contrastante (CURY, 1992, p. 60).
\end{abstract}

Nesta segunda obra didática, o diálogo com a teoria é escasso e quando há se dá de forma bastante indireta, sem qualquer tipo de referência aos teóricos, o que evidencia, ainda mais, a perspectiva historiográfica do material.

Seu primeiro capítulo - "Artes" - contextualiza a arte e o artista, remonta os primórdios da arte geral para, em seguida, discutir a escrita e a arte literária, também sob um viés histórico. Após inúmeras e exaustivas buscas, chegamos ao seguinte trecho:

Na linguagem literária, as palavras são empregadas de modo especial, com maior significação e expressividade. $\mathrm{O}$ escritor não somente recria a realidade, mas também atribui novos valores às palavras. Nesse sentido, podemos dizer que a linguagem literária é fortemente conotativa (OLIVEIRA, 2012, p. 20, grifo nosso). 
Mais uma vez, a linguagem é posta como "modo especial", devido a seu caráter conotativo. Aqui, assim como na primeira obra analisada, temos uma leve, para não dizer distante, referência à teoria. Os formalistas, em vários momentos de suas discussões, problematizam a questão da linguagem literária. Seus estudos, por outro lado buscam, de forma intensa, entender, a fundo, as peculiaridades desse tipo específico de linguagem. Assim, não seria muita redução conceituá-la superficialmente apenas como uma linguagem especial, com maior expressão e significado? Afirmações tão gerais escondem a complexidade de um assunto tão discutido desde o início do século XX. A nosso ver, questão de tamanha complexidade, como é o caso da literariedade, merece o tratamento profundo que lhe é de direito, como aquele iniciado por Eikhenbaum.

Como foi possível observar, o segundo livro, Literatura em contexto: a arte literária luso brasileira, apresenta, em sua estrutura, apenas um ponto que indiretamente dialoga com Eikhenbaum. A noção de "estranhamento", por outro lado, sequer é mencionada. Logo, por mais que a obra seja destinada unicamente ao trabalho com a literatura, adere fortemente à historiografia, pouco dialogando com a teoria.

Em resumo, os dois livros analisados Português: linguagens, de William Roberto Cereja \& Thereza Cochar Magalhães, e Literatura em contexto: a arte literária luso brasileira, de Clenir Bellezi de Oliveira, apresentam reflexos da teoria, mais no primeiro caso, explicitamente por meio da própria teoria apresentada e através da citação direta de seus teóricos, e de forma superficial no segundo, através de um trecho que apenas sugere tal diálogo.

\section{Considerações Finais}

O ingresso do estudante no Ensino Médio nos remete, de imediato, a extremidades relativamente opostas no que diz respeito ao acesso à literatura durante o período escolar. Enquanto na Educação Infantil e no Ensino Fundamental (I e II) o texto literário ganha destaque; no Ensino Médio, é possível perceber, ainda, por meio de breve consulta aos dois livros didáticos analisados, certa predominância na exposição de uma historiografia literária simplificada, reduzindo consideravelmente seu acesso, segundo Cosson (2014, p. 13), a “(...) fragmentos recortados, adaptados ou condensados de gêneros, modalidades, contextos culturais e temas que passam ao largo da literatura". Diante disso, à medida que a literatura, no Ensino Médio, passa a ser vista como um componente curricular a ser apreendido pelo 
estudante tão somente por sua periodização, a escola perde a oportunidade de desenvolver habilidades que o levariam ao desenvolvimento da leitura e da interpretação de obras completas.

A teoria literária, como mostra a análise, aparece sempre em desvantagem, com menos espaço para discussão. Quando aparece direta e/ou indiretamente nas páginas dos livros didáticos recebe um tom de superficialidade que passa ao largo das profundas discussões empreendidas pelos teóricos, sobretudo os do formalismo eslavo que juntamente com a estilística franco-germânica e o new criticism anglo-norte-americano se opõem aos princípios da história literária, fundando o que hoje conhecemos por teoria da literatura.

Zilberman (2005, p. 244), dentre tantos outros pesquisadores, propõe uma abordagem que substitua a tradicional linearidade e unidirecionalidade da exposição da literatura por um trabalho com perspectivas múltiplas. A nosso ver, estender as discussões para além da linearidade histórica, buscando refletir sobre questões inerentes à linguagem e as obras literárias, dialogando com outras perspectivas de estudo, como a própria teoria literária, a literatura comparada, os estudos culturais, nos parece um ótimo caminho para aprofundar as discussões sobre literatura no Ensino Médio, nas escolas públicas e particulares.

\section{REFERÊNCIAS}

CEREJA, William Roberto. Português: linguagens. 4. ed. São Paulo: Atual, 2013.

CHKLOVSKI, Viktor. A arte como procedimento. In: TOLEDO, Dionísio de Oliveira (Org.). Teoria da literatura: formalistas russos. Porto Alegre: Globo, 1973.

COSSON, R. Letramento literário: teoria e prática. 2. ed. São Paulo: Contexto, 2014.

CURY, Maria Zilda Ferreira. Historiografia literária em questão. In: PAULINO, Graça; WALTY, Ivete (Org.). Teoria da literatura na escola: atualização para professores de I e II graus. Belo Horizonte: UFMG/FALE/Departamento de Semiótica e Teoria da Literatura, 1992.

EIKHENBAUM, Boris. A teoria do "método formal". In: TOLEDO, Dionísio de Oliveira (Org.). Teoria da literatura: formalistas russos. Porto Alegre: Globo, 1973.

GINZBURG, Carlo. Olhos de madeira: nove reflexões sobre a distância. São Paulo: Companhia das Letras, 2001.

OLIVEIRA, Clenir Bellezi de. Literatura em contexto: a arte literária luso-brasileira. São Paulo: FTD, 2012.

OLIVEIRA, Thiago Laurentino de. O formalismo russo em linhas gerais. Disponível em: $<$ http://teorialiterariaufrj.blogspot.com.br/2009/06/o-formalismo-russo-em-linhas gerais.html>. Acesso em: 13 jul. 2017. 
RODÓ, José Henrique. O ensino da literatura [1908]. In: SOUZA, Roberto Acízelo de (Org.). Uma ideia moderna de literatura: textos seminais para os estudos literários (1688-1922). Chapecó: Argos, 2011, p. 602-05.

SOUZA, Roberto Acízelo de. História da literatura: trajetória, fundamentos, problemas. São Paulo: É Realizações, 2014.

ZILBERMAN, R. A universidade brasileira e o ensino das literaturas de língua portuguesa. In: BORDINI, M.; REMÉDIOS, M. L.; ZILBERMAN, R. Crítica do tempo presente. Porto Alegre: IEL, 2005. 